\title{
Assessment of Pest Control Services by Vertebrates in Nigerian Subsistence Maize Farms
}

\author{
Murna Tela ${ }^{\mathrm{a}, \#}$, Will Cresswell ${ }^{\mathrm{b}}$ and Hazel Chapman ${ }^{\mathrm{c}}$ \\ aDepartment of Biological Sciences, Gombe State University, Gombe, Nigeria \\ ${ }^{\mathrm{b}}$ School of Biology, University of St Andrews, Fife, Scotland, UK \\ ${ }^{\mathrm{c} S}$ chool of Biological Sciences, University of Canterbury, Christchurch, New Zealand
}

\#Corresponding author E-mail: elmursha@yahoo.com

\begin{abstract}
Global conversion of patches of natural vegetation into agricultural land is reducing the ecosystem services provided by natural patches dwelling species to farmers. For sub-Saharan African subsistence farmers, such a reduction in pest control services by birds may be a significant disadvantage. Here we explored to what extent birds provide pest control services to the staple crop maize (Zea mays) on small subsistence farms on the Mambilla Plateau of Taraba State, Nigeria. We used exclosure experiments (maize crops with and without birds) to model how birds influenced crop yield. We found that excluding birds from maize significantly reduces crop yield, although the lack of a direct correlation between bird abundance and crop yield suggests that other taxa, such as bats, may also be important pest predators. Our results suggest that in this subsistence farming landscape, natural pest control of maize from vertebrates does occur, but further research is needed to understand the specific control agents and the role of patches of natural vegetation as habitat for them.
\end{abstract}

Keywords: Subsistence maize farm, exclosure experiment, birds, pest control services, crop productivity

Link to supplementary material and data file: https://bit.ly/3Ak9E6R

\section{INTRODUCTION}

Africa's human population is growing faster than anywhere else and is predicted to comprise almost two-thirds of the global population increase between 2020 and 2050 (WPP 2019). In sub- Saharan Africa, increased food production associated with such population growth is predicted to come from subsistence farms rather than from increased farm intensification (Davis et al. 2017; Laurance et al. 2014). Thus, patches of natural vegetation will continue to be converted to crop-land with major

\begin{tabular}{|l|l|}
\hline \multicolumn{2}{|c|}{ Access this article online } \\
\hline Quick Response Code: & Website: \\
\hline & www.conservationandsociety.org.in \\
\cline { 2 - 3 } & \\
\hline
\end{tabular}

implications for biodiversity and associated ecosystem services (Malhi et al. 2014; Whelan et al. 2015; Whelan et al. 2008). In Africa, biodiversity hotspots, including the Cameroon highlands (Ezealor 2002; Fishpool and Evans 2001) are especially vulnerable because they share both a high propensity for farmland expansion and high levels of endemism (Zabel et al. 2019).

One way to counter habitat loss and protect biodiversity is to demonstrate to farmers the economic benefit of maintaining patches of natural habitat for the ecosystem services they provide (Garcia et al. 2020; Marcacci et al. 2020). This approach has been successful in several locales across a range of cropping systems; for example, several recent studies have shown insectivorous birds to be effective controllers of invertebrate pests in large scale farming operations and plantations in tropical agroecosystems (Classen et al. 2014; Karp et al. 2013; Maas et al. 2015). Birds have been shown to directly reduce infestation rates of invertebrates and indirectly increase crop productivity in coffee plantation and apple orchard (Kellermann et al. 2008; Mols and Visser 2002).

Copyright: (C) Tela et al. 2021. This is an open access article distributed under the terms of the Creative Commons Attribution License, which permits unrestricted use and distribution of the article, provided the original work is cited. Published by Wolters Kluwer - Medknow, Mumbai | Managed and supported by the Ashoka Trust for Research in Ecology and the Environment (ATREE), Bangalore. For reprints contact: WKHLRPMedknow_reprints@wolterskluwer.com 
However, in sub-Saharan Africa a dearth of studies means that very little convincing evidence is available to subsistence farmers to suggest that conserving natural habitats may benefit crop yield. Only one study that we are aware of, from East Africa, has assessed the role of insectivorous birds in regulating herbivorous arthropods on maize farms (Otieno et al. 2019). For other crops, a study from Kenya (Miligan et al. 2016) demonstrated that both forest birds and ants made significant contributions to pest control in highland coffee plantations, and Ndang'ang'a et al. (2013) quantified the contribution of insectivorous birds in controlling insect pests on the brassica crop Oleracae acephala.

Across sub-Saharan Africa, Zea mays is the second most-produced staple crop (FAO 2017), with the land area used for growing maize having increased by $60 \%$ between 2007 and 2017 (Santpoort 2020). Most producers are small, often subsistence farmers who cannot afford pesticides (Zhang et al. 2018), a common situation in Nigeria (Richard 2014). In sub-Saharan Africa, maize is attacked by a myriad of invertebrate pests which contribute to lower crop yields to well below the worldwide average (SFSA and Syngenta 2020). Herbivorous insects of maize, such as the maize stem borer (Lepidoptera: Busseola fusca) and pink stalk borer (Lepidoptera: Sesamia calamistis) are major pests (Adamu et al. 2015; Oben et al. 2015; Zakari et al. 2014) and in Nigeria can reduce yields by 12 - 50\% (Adamu et al. 2015). How vertebrates such as birds, bats and rodents contribute to pest control in subsistence food crops such as maize (Cadoni and Angelucci 2019), needs to be better understood.

In Nigeria, subsistence farms often form a patchwork within a semi-natural environment comprising degraded grassland, scrubland or patches of natural vegetation that are at varying distances from the farmlands. Crop plants (e.g., maize crop plants) may depend on these habitats for pest control services by vertebrates because trees provide breeding habitats or refuges. Here we chose to focus on birds as control agents because among vertebrates, birds exhibit the most diverse range of ecological functions (Sekercioglu 2006), and are known to provide important ecosystem services elsewhere (Whelan et al. 2015) .

Our overall hypothesis was that, birds, by predating on invertebrate pests of maize, allow for increased maize yield. We made two predictions: 1) that the proportion of cob and leaf damage caused by insect herbivory on crops will be higher in the bird excluded treatment, which will in turn negatively affect crop yield, and 2) that crop yield will be highest where birds are most abundant. Our specific objectives were to test; 1) whether excluding vertebrates (e.g., birds and bats) from maize crops leads to a reduction in crop yield and, 2) if there is a relationship between bird abundance and maize crop yield.

\section{MATERIALS AND METHODS}

Study area

Our study took place in the farmlands along the north western escarpment of the Mambilla plateau in Taraba State $\left(7.16^{\circ} \mathrm{N}, 11.66^{\circ} \mathrm{E}\right), \mathrm{SE}$ Nigeria, close to the Nigerian Montane Forest Project (NMFP) field station. There is a distinct wet and dry season with a mean annual rainfall of around 1700mm (Chapman and Chapman 2001). The minimum average monthly temperature ranges from $15.5-18.5^{\circ} \mathrm{C}$ and the maximum from $27.5-30.5^{\circ} \mathrm{C}$ (Matthesius et al. 2011). The plateau, with an average elevation of $1,600 \mathrm{~m}$ is characterised by gently undulating hills covered in overgrazed Sporobilis grassland, with a loose patchwork of small subsistence farms mostly associated with villages and patches of natural vegetation. Annual food crops grown in the farms include maize, ginger (Aframomum melegueta), groundnuts (Arachis hypogea), kidney beans (Phaseolus vulgaris), potatoes (Soloanum tuberosum) and yam (Dioscorea rotundata). A year-long bird survey, conducted as part of a wider study associated with this research, showed that insectivorous birds are an important component of the bird fauna, comprising over $50 \%$ of all avian species in the area (Tela 2019). For the experiment, we selected 20 maize farms situated at varying distances from the natural habitats (Figure 1). All farms were free from pesticide use and were at least $200 \mathrm{~m}$ apart from each other. The willingness (or otherwise) of farmers to allow work on their land, placed a limit on the number of farms included in the study.

\section{Study design and sampling}

Exclosure experiments were conducted during the wet season April - October 2017, when maize is traditionally cultivated on the Mambilla Plateau. In each of the 20 farms studied, farmers had planted their maize seeds in early April as part of their routine maize planting schedules. Thereafter, we established one $20 \times 10 \mathrm{~m}$ plot on each farm and subdivided each plot into three $6.7 \times 10 \mathrm{~m}$ subplots. One of the three subplots was retained as a control treatment (open access), one was designated as a bird exclusion treatment, and one as birds + insects-excluded treatment. The exclosures placed in

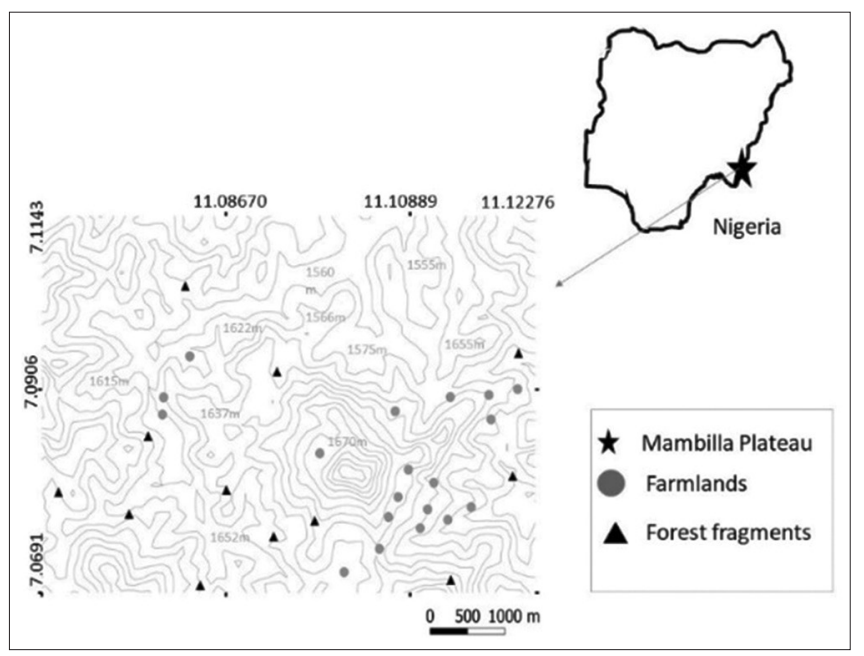

Figure 1

Map of Nigeria and the location of the experimental site on Mambilla Plateau, Nigeria 
the $6.7 \times 10 \mathrm{~m}$ subplots were each approximately $4 \times 4 \times 4 \mathrm{~m}$, with a distance of $2.5 \mathrm{~m}$ between each subplot.

All cages were built with wooden frames; the bird-only exclusion cages were covered with agricultural wire netting with pore size of $0.8 \mathrm{~mm} \times 1.2 \mathrm{~mm}$, allowing for insects to enter while excluding birds. The bird + insect exclusion cages were covered with mesh of pore size $0.1 \mathrm{~mm} \times 0.1 \mathrm{~mm}$. The cages were placed in the respective subplots as soon as the maize seedlings germinated. Each cage was placed over three maize plants and staked down. Care was taken to arrange the netting to make leaves inaccessible to hovering birds and deny entry of ground-foraging birds. In the control (i.e., open access) three maize plants, of similar proximity to each other as the three plants in the exclusion cages were identified and tagged with pink ribbons as control plants.

For each treatment, when the maize cobs were ripe, we harvested the ripe maize cobs from each of the three plants in each of the three treatments across the 20 farms twenty-one weeks after planting, in September. First, the number of cobs from the three experimental crops in each treatment was counted, and the husks were peeled off. Any holes in the kernels, caused by invertebrate herbivores (hereafter referred to as damaged cobs of maize), were also counted and recorded. The cobs were then dried on a mat exposed to sun and wind, until they reached a constant weight, using a digital Camry mechanical weighing scale (NS $5-20 \mathrm{~kg}$ ). At the time of harvest, we also assessed damage by phytophagous insects on each plant from each treatment. Leaf damage was visually estimated as the percentage of leaf area damaged by herbivores, relative to the total leaf area (Morrison and Lindell 2012). We considered damage as perforated, skeletonised, curled or partly cut leaves (Lemessa et al. 2015; Morrison and Lindell 2012; Van Bael et al. 2003). To control for possible differences in leaf damage before the experiment began, we checked to see if there was any leaf damage following the sprouting of maize plants but found none.

\section{Bird abundance assessment and classification}

We sampled birds in each location using point counts (Bibby et al. 2000). Each farm was surveyed once per week between 6:30 am to 10:30 am, logistically we were unable to work at night during our study. We spent 10 minutes on focal observation of birds and recorded birds within a $50 \mathrm{~m}$ radius at each experimental plot. Observations were made along the edge of the experimental plots to avoid any form of disturbance. In the analysis, all birds that included insects as part of their diet, even though insects may not be a primary component of their diet, were included in the dataset (Borrow and Demey 2001; Bregman et al. 2014; Wattel 1993). These species make up the trophic functional group that is likely to be providing pest control services to the farmlands.

We classified each bird to habitat categories according to whether they are 1) farmland 2) forest fragments or 3) in both farmland and forest fragments, using habitat association information found in Bibby et al. (2000), and Wattle et al.
(2003). We also categorised each bird occurrence within the understory (ground-foraging omnivores), midstory (aerial foliage gleaners) and the upper story (upper strata). This is important because tropical studies have shown that 1) the understory insect eating birds are highly impacted by natural habitat modifications (Bregman et al. 2014; Buechley et al. 2015) making them good indicators of habitat quality (Whelan et al. 2015), and 2) the understory insect eating birds contribute to pest control services to coffee farmers in East Africa and in other regions of the world (Buechley et al. 2015; Otieno et al. 2019), and may be of economic importance to maize farmers in Nigeria (see Appendix 2 for a list of species and their classification).

\section{Statistical analysis}

All statistical analyses were carried out using the R statistical package version 3.5.6 (R Core Team 2018). We calculated the means and standard errors of crop yield, cobs damage and leaf damage across the three treatment (Table 1), and then we used general linear mixed effects models (GLMMs) to test whether the abundance of birds had any effect on crop productivity as measured by crop yield, leaf damage and cobs damage. Our initial experiments included three treatments: 1) open access (subsequently referred to as control) with no exclusion (birds + insects present), 2) birds only excluded, 3) birds + insects excluded. Unexpectedly, crop yield, cob and leaf damage measures for both exclosure types were very similar, suggesting that insects were not excluded completely from the cages that were intended to exclude both birds and insects (Appendix 1). Therefore, because this was considered to be a failure of experimental implementation, we re-ran the models using bird exclusion and control treatments only and concentrated on the effects of excluding birds versus the control treatment only.

To address the objectives of the experiment, we used general linear mixed effects models (GLMMs) to test whether crop productivity, as measured by crop yield, cob damage and proportion of phytophagous leaf damage, was influenced by 1) bird exclusion and 2) bird abundance. For each objective we modelled crop productivity as a function of the abundance of insectivorous birds, with treatment and bird abundance as fixed effects and plot as a random effect. All model selections were carried out using the information-theoretic approach based on Akaike's Information Criterion (Burnham and Anderson 2003). Simplification of models was undertaken using deletion of least significant effects from an initial full model. In all cases, a statistical significance level of $p<0.05$ was chosen to reject the null hypothesis.

\section{RESULTS}

We recorded 3,343 birds belonging to 165 different species across the 20 farmlands. Over $50 \%$ of the bird species included insect as part of their diet (Tela 2019). Eighty-seven species are understory insect eating birds, 60 species are midstory insect 
Table 1

The mean ( \pm SE) of crop yield, damaged cobs and \% leaf damage in three experimental treatments (insect and birds excluded from crops, birds only excluded from crops and crops accessible to birds) across 20 farmlands

\begin{tabular}{|l|c|c|}
\hline \multicolumn{3}{|c|}{ Replications (40 points) } \\
\hline Parameters & Insect and birds excluded & Birds excluded \\
\hline Crop yield (g) & $244.13 \pm 35.67$ & $306.33 \pm 47.87$ \\
\hline Cobs with damage & $0.025 \pm 0.025$ & $0.13 \pm 0.064$ \\
\hline Percentage of leaf damage & $0.55 \pm 0.84$ & $2.075 \pm 1.047$ \\
\hline
\end{tabular}

eating birds and 18 species are upper strata species. In total, we recorded a crop yield of $28,063 \mathrm{~g}$ from the control treatment and $16,030 \mathrm{~g}$ from the bird excluded treatment.

The exclusion of birds from the maize plots led to reduced crop yield and increased cob and phytophagous leaf damage (Table 1).

While crop yield was significantly higher in open plots than in bird-excluded ones, it did not increase as insectivore abundance increased (Table 2A and Figure 2). Moreover, there were no significant differences in cob damage across treatments or with abundance of insectivorous birds (Table 2B). However, leaf damage was marginally significatly lower in the open treatment relative to the bird excluded treatments (Table 2C).

\section{DISCUSSION}

Our study adds to only a handful of previous studies from Africa into crop pest control by birds (Milligan et al. 2016; Ndang'ang'a et al. 2013; Otieno et al. 2019) and is the first from sub-Saharan Africa, as far as we know, to assess the effect of pest control provided by birds on maize yield in subsistence farmlands. We have demonstrated that excluding birds as well as other vertebrates from maize plants at our study area leads to a significant reduction in crop yield compared with plants on which vertebrates have open access. We have therefore strong evidence that natural pest control may increase crop yield.

About $90 \%$ of the birds recorded in our study use both the farmlands and patches of natural vegetation. It is possible that some of the birds from the natural habitats were foraging in the maize farms, providing valuable ecosystem services. On the other hand, the farms may serve as stepping-stone or corridors for forest birds searching for more suitable habitat, emphasising the need for effective conservation of seminatural habitats in montane regions.

With regard to guild, our maize farms support a high number of understory insect eating birds e.g., the Rufous-naped Lark (Mirafra Africana), Common (African) Stonechat (Saxicola torquatus), Northern Grey-headed Sparrow (Passer griseus) and Common Bulbul (Pyconotus barbatus). This particular group of bird species may be of economic importance to maize farmers in Nigeria, as shown in other region of Africa e.g., in East African coffee farms (Buechley et al. 2015). However, the understory insect eating birds are among the most susceptible of groups to disappear from natural habitat disturbance (Arcilla et al. 2015; Cordeiro et al. 2015; Powell et al. 2015; Şekercioḡlu et al. 2002). Therefore, in order to conserve these birds for pest control
Table 2

The relationship between crop yield, damaged cobs and percentage leaf damage and bird abundance in the two treatments (birds only excluded from crops and crops accessible to birds) across 20 farmlands

\begin{tabular}{|l|c|c|c|c|}
\hline Variables & Estimate & SE & $\boldsymbol{t}$ & $\boldsymbol{P}$ \\
\hline A. Crop yield model (AIC=1145.62) & & & & \\
\hline (Intercept) & 216.82 & 146.67 & 1.48 & 0.147 \\
\hline Insectivorous birds & 6.29 & 9.74 & 0.65 & 0.522 \\
\hline Open access & 466.68 & 57.21 & 8.16 & $<\mathbf{0 . 0 0 1}$ \\
\hline B. Cobs with damage model (AIC=102.02) & & & & \\
\hline (Intercept) & 0.11 & 0.19 & -0.59 & 0.556 \\
\hline Insectivorous birds & 0.017 & 0.012 & 1.35 & 0.183 \\
\hline Open access & -0.05 & 0.1 & -0.51 & 0.613 \\
\hline C. Leaf damage model (AIC=522.26) & & & & \\
\hline (Intercept) & 3.06 & 2.6 & 1.18 & 0.247 \\
\hline Insectivorous birds & -0.03 & 0.17 & -0.18 & 0.859 \\
\hline Open access & -2.63 & 1.36 & -1.94 & 0.06 \\
\hline
\end{tabular}

Notes: Bird excluded was set as the intercept. Significant $P$ values is given in bold.

services to farmers in a long term, it is important to conserve semi natural habitats in Nigerian agricultural landscape. We also recorded a good number of the midstory insect eating birds, most of which are aerial foliage gleaners and may play an important role in insect pest control in the maize farms, e.g., Common Fiscal (Lanius collaris), Orange-tufted Sunbird (Cinnyris bouvieri), and the Cisticolas (in large numbers).

We found a total drop in maize yield of $12.03 \mathrm{~kg} / 4.5 \mathrm{~km}^{2}$ when plants were caged and protected from birds, relative to the yield from uncaged plants. Based on these data, and the dollar value of maize in local markets, we estimate that losing birds from Mambilla plateau farms would cost farmers between 14 - 25 US\$ per hectare. This is based on the following assumptions and reasonings; maize is worth approximately $1.2 \mathrm{US} \$ / \mathrm{kg}$ (i.e., the price of foodstuffs in Nigeria 2020). The values used in our estimations were based on local maize prices in rural areas. However, given that the price of maize substantially increases as it is traded from farm to wholesalers and ultimately to retailers and consumers (Eyitayo et al. 2019; Kaminski et al. 2013), the actual ecosystem service of insect pest control by birds or other vertebrates may be substantially higher in situations where this supply chain operates. In addition to the benefit of natural pest control on crop yield is the reduced need for pesticides. This is beneficial both in reducing pesticide dollar costs and their detrimental effects on both human health and the environment (Muller et al 1997).

Our study, in demonstrating that natural pest control may increase crop yield on Mambilla subsistence farms, has set 


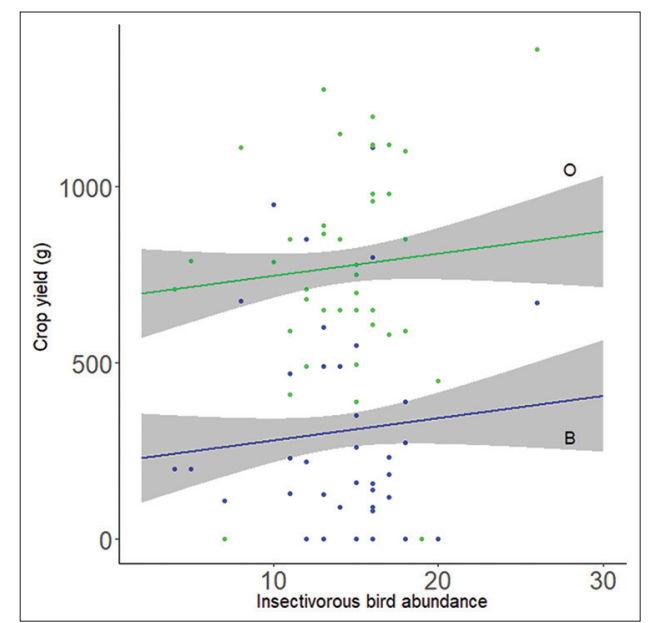

Figure 2

Relationship between crop yield and abundance of insectivourous birds across treatments; $O$ - open access and B - Birds excluded. Shaded areas represent \pm 1 SE. Predicted lines plotted from the model in Table 2A: change in yield with abundance is not significant, but differences according to treatment are

the scene for future research. There were several limitations to our study. First, our exclosure experiments were not all successful- future work must make sure that there is a third treatment with both birds + insects excluded. This is important because it should theoretically tell us what proportion of the change in yield is directly due to insects. Secondly, the birds + insects exclosure itself may have decreased yield in this treatment because of the negative effect of the mesh on growing conditions (e.g., through shading or microclimate). Another potential effect of the mesh may have been on pollination; maize is mostly wind pollinated and the cage meshing may have slowed wind flow past the maize. Consequently, we have based our conclusions on just the data from control (open) plots versus bird excluded plots. Thirdly, we did not identify which pest species were most attracted to maize, nor the insectivores most active on maize plants.

The lack of any relationship between insectivore abundance and yield in our study may be partly due to the ecology of maize and/or Mambilla subsistence farmlands, our experimental design) or perhaps, a combination of both ecology and design limitations. For example, not all insectivorous birds necessarily include maize plants as an important source of insects, especially if other crops in the system are more attractive to phytophagous insects. Possibly one, or a few birds present were responsible for the observed levels of pest control (e.g., Jedlicka et al. 2011; Maas et al. 2015). Alternatively, there may be other key biocontrol insectivores of maize pests involved, such as bats and possibly rodents. Bats are known to predate on phytophagous insects elsewhere (Williams-Guillén et al. 2008) and are common in the farmlands of our study area (pers. obs. MT, HC). Moreover, many herbivorous insects are nocturnal (Maas et al. 2013; Morrison and Lindell 2012), as are bats. Due to logistical constraints, we were unable to test for bats - this would have involved going out at dawn and dusk to remove and replace cages and the security situation on the plateau did not allow for this. Nevertheless, our exclosure experiments were closed all day and night, so technically we excluded both birds and bats. Although, rodents can also improve crop yields by feeding on insect pests, rodents are known to cause significant damage to a range of agricultural crops (e.g., maize, wheat, rice and groundnuts) worldwide (see Brown et al. 2007; Labuschagne et al. 2016). For example, the house mouse (Mus musculus) is responsible for most of the postharvest crop damage caused by rodents in Africa (Ognakossan et al. 2016). Thus, future studies should investigate the relationship between the presence of rodents and crops in Nigerian subsistence farmlands.

While we did not show a strong effects of excluding birds on cob and leaf damage, as might have been expected given the drop in yield, insect damage to crops often extends beyond leaf herbivory (Morrison and Lindell 2012). For example, a significant proportion of insect pests of maize may not attack leaves, or at least do not make holes that significantly reduce leaf surface area (De Groote 2002; Ofor et al. 2009), but may attack maize stems (Tremblay et al. 2001). For example, in the case of the stem borer, birds may catch the moths and therefore reduce the number of larvae in the stems. Aphids are phloem-feeding insects (Morrison and Lindell 2012) that can severely damage plants, leading to reduced yield, yet do not necessarily reduce leaf surface area by creating holes (Goggin 2007; Zangerl et al. 2002).

Future research should seek to establish if the ecosystem and economic services provided by birds in maize farms are widespread in Nigerian farmlands and other maize- growing regions across Africa. If they are, and if birds (or bats) depend on patches of natural vegetation, and if this is explained to local communities, it may provide a powerful incentive for conservation of natural habitat.

\section{Author contribution statement}

Conception and design of the research: MT, WC, HC. Data collection: MT. Data analysis: MT, WC. Drafting of manuscript: MT. Intellectual contents to the drafts and critical revision of manuscript: $\mathrm{MT}, \mathrm{WC}, \mathrm{HC}$. Final approval of the version to be published: MT, WC, HC.

\section{ACKNOWLEDGEMENTS}

We thank the Reviewers and Editor for their valuable comments on an earlier draft of this manuscript. We thank the assistants who helped with fieldwork in Nigeria; Yakubu Vugeh and Usman Bashiru. We are grateful to farmers who allowed us work on their farmlands. We thank the Nigerian Montane Forest Project (NMFP) for logistics support.

\section{Declaration of competing/conflicting interests}

The authors declare no competing interests in the conduct of this research. 


\section{Financial Disclosure}

MT was supported by a studentship funded by New Zealand Ministry of Foreign Affairs and Trade (MFAT) through the University of Canterbury, and A.G Leventis educational research grants for doctoral candidates. The funders had no role in study design, data collection and analysis, decision to publish, or preparation of the manuscript.

\section{Research Ethics Approval}

Not applicable. This research does not require an ethics approval.

\section{Data Availability}

All data are fully available without restriction. We have provided the data in a separate supplementary information file (cs_20_213_Tela et al_data file.xlsx).

\section{REFERENCES}

Adamu, R., M. Usman, and R. Isah. 2015. Evaluation of four insecticides foliar sprays for the management of maize stem borer, Busseola Fusca (F.) on maize irrigated using furrow and basin irrigation methods at Kadawa, Kano State Nigeria. FUTA J. Res. Sci.(1): 7-14.

Arcilla, N., L.H. Holbech, and S. O'Donnell. 2015. Severe declines of understory birds follow illegal logging in Upper Guinea forests of Ghana, West Africa. Biological Conservation 188: 41-49.

Borrow, N. and R. Demey. 2004. Field guide to the birds of western Africa. London: Bloomsbury Publishing.

Bregman, T. P., C.H. Sekercioglu, and J.A. Tobias. 2014. Global patterns and predictors of bird species responses to forest fragmentation: implications for ecosystem function and conservation. Biological Conservation 169: 372-383.

Brown, P. R., N.I. Huth, P.B. Banks, and G.R. Singleton. 2007. Relationship between abundance of rodents and damage to agricultural crops. Agriculture, Ecosystems \& Environment 120(2-4): 405-415.

Buechley, E. R., C.H. Şekercioğlu, A. Atickem, et al. 2015. Importance of Ethiopian shade coffee farms for forest bird conservation. Biological Conservation 188: 50-60.

Bibby, C.J., N.D. Burgess, D.A. Hill et al. 2000. Bird census techniques. London: Academic Press.

Burnham, K. P.and D.R. Anderson.2003. Model selection and multimodel inference: a practical information-theoretic approach. New York: Springer Science \& Business Media.

Cadoni, P.and F. Angelucci. 2019. Analysis of incentives and disincentives for maize in Nigeria. Gates Open Res 3:668. https://doi.org/10.21955/ gatesopenres.1115498.1.

Chapman, J. and H. Chapman. 2001. The forests of Taraba and Adamawa States, Nigeria. An ecological account and plant species checklist. Christchurch, New Zealand: University of Canterbury.

Cordeiro, N. J., L. Borghesio, M.P. Joho et al. 2015. Forest fragmentation in an African biodiversity hotspot impacts mixed-species bird flocks. Biological Conservation 188: 61-71.

Classen, A., M.K. Peters, S.W. Ferger, et al. 2014. Complementary ecosystem services provided by pest predators and pollinators increase quantity and quality of coffee yields. Proceedings of the Royal Society of London B: Biological Sciences 281(1779): 20133148.

Davis, B. S. Di Giuseppe, and A. Zezza. 2017. Are African households (not) leaving agriculture? patterns of households' income sources in rural Sub-Saharan Africa. Food Policy 67: 153-174.
De Groote, H. 2002. Maize yield losses from stemborers in Kenya. International Journal of Tropical Insect Science 22(2): 89-96.

Eyitayo, A. O., H.K. Ibrahim, S.M. Funke, et al. 2019. The determinants and efficiency of maize crops marketing in Ilorin metropolis. https:// www.researchgate.net/publication/334785124_The_Determinants and_Efficiency_of_Maize_Crops_Marketing_in_Ilorin_Metropolis. Accessed on February 29, 2020.

Ezealor, A. U. 2002. Critical sites for biodiversity conservation in Nigeria: Nigerian Conservation Foundation.

FAO. 2017. FAO and the 17 sustainable development goals. http://www.fao. org/3/a-i4997e.pdf. Accessed on June 9, 2020.

Fishpool, L. D. and M.I. Evans. 2001. Important bird areas in Africa and associated islands: priority sites for conservation. Cambridge: BirdLife International.

Garcia, K., E.M. Olimpi, D.S. Karp et al. 2020. The good, the bad, and the risky: can birds be incorporated as biological control agents into integrated pest management programs? Journal of Integrated Pest Management, 11(1): 11.https://doi.org/10.1093/jipm/pmaa009.

Goggin, F. L. 2007. Plant-aphid interactions: molecular and ecological perspectives. Current Opinion in Plant Biology 10(4): 399-408.

Kaminski, J., A. Elbehri, and J. Zoma. 2013. An analysis of maize value chain and competitiveness in BurkinaFaso: implications for smallholderinclusive policies and initiatives. In: Rebuilding West Africa's food potential. Rome, Italy: FAO/IFAD.

Karp, D. S., C.D. Mendenhall, R.F. Sandí, et al. 2013. Forest bolsters bird abundance, pest control and coffee yield. Ecology Letters 16(11): 1339-1347.

Kellermann, J. L., M.D. Johnson, A.M. Stercho et al. 2008. Ecological and economic services provided by birds on Jamaican Blue Mountain coffee farms. Conservation Biology 22(5): 1177-1185.

Labuschagne, L., L.H. Swanepoel, H. Taylor et al. . 2016. Are avian predators effective biological control agents for rodent pest management in agricultural systems? Biological Control 101: 94-102. doi:10.1016/j. biocontrol.2016.07.003.

Laurance, W. F., J. Sayer, and K.G. Cassman. 2014. Agricultural expansion and its impacts on tropical nature. Trends in Ecology \& Evolution 29(2): 107-116.

Lemessa, D., U. Samnegård, P.A. Hambäck, et al. 2015. Tree cover mediates the effect on rapeseed leaf damage of excluding predatory arthropods, but in an unexpected way. Agriculture, Ecosystems \& Environment 211: 57-64.

Maas, B., Y. Clough, and T. Tscharntke. 2013. Bats and birds increase crop yield in tropical agroforestry landscapes. Ecology Letters 16(12): 1480-1487.

Maas, B., T. Tscharntke, S. Saleh, et al. 2015. Avian species identity drives predation success in tropical cacao agroforestry. Journal of Applied Ecology 52(3): 735-743.

Malhi, Y., T.A. Gardner, G.R. Goldsmith, et al. 2014. Tropical forests in the Anthropocene. Annual Review of Environment and Resources 39(1): 125-159. doi:10.1146/annurev-environ-030713-155141 .

Marcacci, G., J. Gremion, J. Mazenauer, et al. 2020. Large-scale versus smallscale agriculture: disentangling the relative effects of the farming system and semi-natural habitats on birds' habitat preferences in the Ethiopian highlands. Agriculture, Ecosystems \& Environment 289: 106737. https:// doi.org/10.1016/j.agee.2019.106737

Matthesius, A., H. Chapman, and D. Kelly. 2011. Testing for Janzen-Connell effects in a west African montane forest. Biotropica 43(1): 77-83.

Milligan, M. C., M.D. Johnson, M. Garfinkel, et al. 2016. Quantifying pest control services by birds and ants in Kenyan coffee farms. Biological Conservation 194: 58-65.

Mols, C. M. and M.E. Visser. 2002. Great tits can reduce caterpillar damage in apple orchards. Journal of Applied Ecology 39(6): 888-899.

Morrison, E. B. and C.A. Lindell. 2012. Birds and bats reduce insect biomass and leaf damage in tropical forest restoration sites. Ecological Applications 22(5): 1526-1534. 
224 / Tela et al.

Ndang'ang'a, P. K., J.B. Njoroge, and J. Vickery. 2013. Quantifying the contribution of birds to the control of arthropod pests on kale, Brassica oleracea acephala, a key crop in East African highland farmland. International Journal of Pest Management 59(3): 211-216.

Oben, E. O., N.N. Ntonifor, S. Kekeunou, et al. 2015. Farmers knowledge and perception on maize stem borers and their indigenous control methods in south western region of Cameroon. Journal of Ethnobiology and Ethnomedicine 11(1): 1-13.

Ofor, M., I. Ibeawuchi, and A. Oparaeke. 2009. Crop protection problems in production of maize and guinea corn in northern guinea savanna of Nigeria and control measures. Nature and Science 7(12): 8-14.

Ognakossan, K. E., H.D. Affognon, C.M. Mutungi, et al. 2016. On-farm maize storage systems and rodent postharvest losses in six maize growing agro-ecological zones of Kenya. Food Security 8(6): 1169-1189.

Otieno, N. E., S.M. Jacobs, and J.S. Pryke. 2019. Maize-field complexity and farming system influence insectivorous birds' contribution to arthropod herbivore regulation. Biotropica 51(6): , 851-861.

Powell, L. L., N.J. Cordeiro, and J.A. Stratford. 2015. Ecology and conservation of avian insectivores of the rainforest understory: a pantropical perspective. Biological Conservation 188: 1-10. doi:https:// doi.org/10.1016/j.biocon.2015.03.025.

Price of foodstuffs in Nigeria. https://nigerianprice.com/prices-ofcommodities-in-nigeria/. Accessed on September 30, 2020.

R Core Team 2018. R: a language and environment for statistical computing. $\mathrm{R}$ foundation for statistical computing, Vienna, Austria. https://www.Rproject.org/. Accessed on January 28, 2020.

Richard, T. T. 2014. Indigenous farming methods in the Mambilla Plateau of Nigeria: the need for a sustainable maintenance culture policy. Science Journal of Sociology and Anthropology. doi:10.7237/sjsa/272.

Santpoort, R. 2020. The drivers of maize area expansion in Sub-Saharan Africa. how policies to boost maize production overlook the interests of smallholder farmers. Land 9(3): 68 .

Sekercioglu, C.H. 2006. Increasing awareness of avian ecological function. Trends in Ecology \& Evolution 21(8): 464-471.

Şekercioḡlu, Ç. H., P.R. Ehrlich, G.C. Daily, et al. 2002. Disappearance of insectivorous birds from tropical forest fragments. Proceedings of the National Academy of Sciences 99(1): 263-267.
SFSAand Syngenta. 2020. Syngenta foundation for sustainable agriculture. Maize in Africa and the pests problem. https://www.syngentafoundation. org/maize-africa-and-pests-problem. Accessed on July 20, 2020.

Tela, M. 2019. The value of forest fragments in maintaining ecosystems for food security in Sub-Saharan Africa. Ph.D. thesis. University of Canterbury, New Zealand.

Tremblay, A., P. Mineau, and R. Stewart. 2001. Effects of bird predation on some pest insect populations in corn. Agriculture, Ecosystems \& Environment 83(1-2): 143-152.

Van Bael, S. A., J.D. Brawn, and S.K. Robinson. 2003. Birds defend trees from herbivores in a Neotropical forest canopy. Proceedings of the National Academy of Sciences 100(14):, 8304-8307.

Whelan, C. J., C.H. Şekercioğlu, and D.G. Wenny. 2015. Why birds matter: from economic ornithology to ecosystem services. Journal of Ornithology 156(1): 227-238.

Whelan, C. J., D.G. Wenny, and R.J. Marquis.2008. Ecosystem services provided by birds. Annals of the New York Academy of Sciences 1134(1): 25-60.

Williams-Guillén, K., I. Perfecto, and J. Vandermeer. 2008. Bats limit insects in a neotropical agroforestry system. Science 320(5872): 70. doi: 10.1126/ science. 1152944

WPP. 2019. World population prospects 2019, population data, file: population growth rate, median variant tab. https://population.un.org/wpp/. Accessed on April 24, 2020.

Zabel, F., R. Delzeit, J.M. Schneider, et al. 2019. Global impacts of future cropland expansion and intensification on agricultural markets and biodiversity. Nature Communications 10(1): 1-10.

Zakari, S., L. Ying, and B. Song. 2014. Factors influencing household food security in West Africa: the case of Southern Niger. Sustainability 6(3): 1191-1202.

Zangerl, A., J. Hamilton, T. Miller, et al. 2002. Impact of folivory on photosynthesis is greater than the sum of its holes. Proceedings of the National Academy of Sciences 99(2): 1088-1091.

Zhang, W., E. Kato, F. Bianchi, et al. 2018. Farmers' perceptions of crop pest severity in Nigeria are associated with landscape, agronomic and socio-economic factors. Agriculture, Ecosystems \& Environment 259: $159-167$.

Received: 16-Oct-2020; Revised: 29-Jun-2021; Accepted: 29-Jun-2021; Published: 09-Sep-2021 